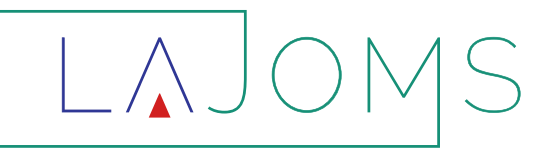

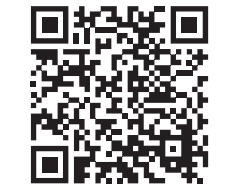

Octubre - Diciembre 2021 Vol. 1, núm. 1 / p. 5
Citar como: Parra AR. Mensaje del Presidente de la Asociación Latinoamericana de Cirugía y Traumatología Bucomaxilofacial. Lat Am J Oral Maxillofac Surg. 2021; 1 (1):

5. https://dx.doi. org/10.35366/101909

\section{Mensaje del Presidente de la Asociación Latinoamericana de Cirugía y Traumatología Bucomaxilofacial}

\author{
Message from the President of the Latin American Association \\ of Buccomaxillofacial Surgery and Traumatology
}

Raúl Parra Armas*
Apreciados Colegas de Latinoamérica y el mundo:

Presentamos a ustedes en esta oportunidad la Revista Científica de ALACIBU, Latin American Journal of Oral and Maxillofacial Surgery, fruto de un arduo esfuerzo de años dentro de nuestra asociación latinoamericana.

Nace con el compromiso de ser una revista moderna, que abarque todas las áreas de nuestra especialidad, sumando un equipo científico de maestros competentes y jóvenes investigadores como cuerpo editor. Creada, además, con el compromiso hacia su independencia de acción, con un reglamento sólido con bases internacionales que la separa de la política, que puede privar en los entes gremiales; además, con la gran apertura para tres lenguas a publicar: español, portugués e inglés.

La Especialidad Quirúrgica de la Cirugía Bucal y Maxilofacial tiene muchos aspectos; su evolución ha llevado al desarrollo de diferentes áreas y técnicas dentro de la misma, la Implantología, Patología Bucal, Deformidades Dento-Esqueletales, Hendiduras Labio-Palatinas o Cirugías Bucales, por citar algunas, lo que ha hecho más profundo y completo el desarrollo de nuestra especialidad y cada área que la enmarca, tal como lo estipulan los PARAMETERS OF CARE de la American Association of Oral and Maxillofacial Surgeons e International Association of Oral and Maxillofacial Surgeons, los cuales estarán incluidos en nuestros artículos.
Los aspectos clínicos de las especialidades son de gran importancia, y LAJOMS enfatiza esto mediante la publicación de artículos de naturaleza, principalmente, clínica. Sin embargo, cualquier especialidad dentro de la medicina o la odontología no puede sobrevivir o progresar sin una investigación básica, por eso hemos creado espacio para la misma en nuestra revista, al igual que la incorporación de un área de Nuevas Tecnologías y Técnicas Quirúrgicas, tal como en las revistas de mayor tiraje en el planeta.

Deseo dar un especial agradecimiento al equipo de MEDIGRAPHIC, por su profesional trabajo para la construcción de esta revista. A los Doctores Luiz Fernando Lobo (Brasil) y Juan José Trujillo (México) por la fabricación de la estructura de LAJOMS con base en su experiencia y, finalmente, al Dr. Henry García (Venezuela), por el desarrollo desde hace ya algunos años del proyecto de la revista, buscando desde el inicio tener la mejor posible y de mayor alcance para todos los Cirujanos Bucales y Maxilofaciales de Latinoamérica y del mundo.

Sigamos adelante, ALACIBU SOMOS TODOS.

Correspondencia:

Raúl Parra Armas

E-mail: raulparra81@hotmail.com

\footnotetext{
* Presidente de la Asociación Latinoamericana de Cirugía y Traumatología Bucomaxilofacial (ALACIBU).
} 